\title{
Hypertonic saline alters ion transport across the human airway epithelium
}

\author{
P.G. Middleton, K.A. Pollard, J.R. Wheatley
}

Hypertonic saline alters ion transport across the human airway epithelium. P.G. Middleton, K.A. Pollard, J.R. Wheatley. (C) ERS Journals Ltd 2001.

ABSTRACT: Aerosolized hypertonic saline is currently being investigated as a new agent for the treatment of impaired mucociliary clearance which occurs in many respiratory diseases. Mannitol aerosols, in particular dry powder inhalers, have been proposed as an alternative treatment to saline, offering the same osmotic load with other benefits. However, the effects of these hypertonic aerosols on airway epithelial ion transport processes have not been tested in human subjects in vivo. This report examines the effect of these solutions on airway ion transport using the nasal potential difference (PD) technique.

Seven healthy nonsmoking adult volunteers were studied. On different days, a doseresponse curve was constructed for the saline added to Krebs N-[2-hydroxyethyl] piperazine-N'-[2-ethanesulphonic acid] (HEPES) diluent. The reversibility of this saline effect was measured, and the response to additional saline $(500 \mathrm{mM})$ and mannitol (1 M) compared.

Hypertonic saline decreased nasal PD in a dose-related manner, with mean (SEM) decreases in PD (less negative) of $6.6(1.5), 7.6(1.6), 10.0(2.0), 13.1(2.9)$ and 14.8 (3.2) $\mathrm{mV}(\mathrm{n}=4)$ for addition of $150 \mathrm{mM}, 250 \mathrm{mM}, 500 \mathrm{mM}, 1,200 \mathrm{mM}$ and $2,000 \mathrm{mM}$ $\mathrm{NaCl}$ to the Krebs HEPES diluent, respectively. The effect of hypertonic saline was fully reversible with washout for $3 \mathrm{~min}$ (presaline $15.9(0.5) \mathrm{mV}$, postwashout 15.8 (1.1) $\mathrm{mV},(\mathrm{n}=4))$. The hypertonic saline response was rapid in onset, sustained for at least $4 \mathrm{~min}$, and decreased PD from $13.7(1.7) \mathrm{mV}$ to $5.1(1.3) \mathrm{mV}(\mathrm{n}=7, \mathrm{p}<0.001)$. In contrast, addition of mannitol to the perfusate did not significantly alter nasal PD, with a nonsignificant trend towards an increase (more negative) in the PD, (premannitol 13.9 (1.6) $\mathrm{mV}$, postmannitol $15.3(2.0) \mathrm{mV}, \mathrm{n}=7$ ).

As the osmotic stimulus of the $1 \mathrm{M}$ mannitol is similar to that of the $500 \mathrm{mM}$ sodium chloride, the divergent nasal potential difference responses suggest that the response to the saline was specific to the sodium chloride itself and not the simultaneous change in osmolarity. This demonstrates that the human airway epithelium in vivo can respond to topical hypertonic saline independent of the altered osmolarity.

Eur Respir J 2001; 17: 195-199.
Cystic Fibrosis Unit, Dept of Respiratory Medicine, Westmead Hospital, Westmead, 2145, NSW, Australia.

Correspondence: P. G. Middleton, Clinical Senior Lecturer, University of Sydney, Director, Cystic Fibrosis Unit, Westmead Hospital, Westmead, 2145, NSW, Australia.

Fax: +61 298457286

Keywords: Airway epithelium chloride

potential difference

sodium

Received: May 152000

Accepted after revision August 182000

PGM was an Applied Health Sciences Research Fellow, and the study was supported by the Australian Cystic Fibrosis Association, the Government Employees Medical Research Fund and the Asthma Foundation of NSW.
The human airways are covered by a thin layer of fluid, the airway surface liquid (ASL), which protects the underlying epithelial cells from drying, and traps inhaled airborne particles and bacteria. The ASL is thought to comprise a watery periciliary or sol layer, over which floats the gel or mucous layer. Though the exact composition and volume of these 2 layers is currently debated, the ASL is thought to be largely regulated by the ion transport processes across the airway epithelium, namely sodium absorption and chloride secretion. Optimal functioning of the ASL is required to maximise mucociliary clearance (MCC), preventing accumulation of mucous and inhaled particles. Retained mucous and particles are a site for bacterial infection, which can then lead to airflow limitation, chronic cough and airway damage.

As impaired MCC is thought to be involved in the pathogenesis of a number of respiratory disorders, treatments have been devised to improve MCC through physical removal of the retained secretions or the use of pharmacological agents. Chest physiotherapy, an example of physical removal of secretions, is extremely effective, but expensive and time consuming in the long term. For this reason a number of pharmacological therapies have been developed to increase MCC.

Recently, interest has focussed on the use of nebulised therapy, in particular hypertonic saline and mannitol, as potential new treatments to increase MCC. Topical application of hypertonic saline via nebuliser has been shown to increase MCC in patients with cystic fibrosis (CF) [1] and a 2 week clinical trial has demonstrated that $10 \mathrm{~mL}$ of $6 \%$ saline improved symptoms and lung function [2]. Similarly inhaled mannitol has been shown to increase MCC in subjects with CF [3] and idiopathic bronchiectasis [4]. However, the mechanism of action of both hypertonic saline and mannitol remains speculative. Whilst it has been hypothesised that the aerosols provide an osmotic 
load to the ASL, no studies have examined the effects of hypertonic saline and mannitol on airway epithelial ion transport in human subjects.

The nasal potential difference (PD) technique, which involves passage of a small exploring electrode along the floor of the nose, allows in vivo measurement of ion transport across the human airway epithelium, bypassing the difficulties of in vitro techniques. The nasal PD technique has previously been used to study the effect of topical antibiotics on human airway epithelial ion transport [5], and to investigate potential new aerosol therapies for CF [6]. In the current study, the effects of topical application of hypertonic saline and mannitol on nasal PD have been investigated, demonstrating that saline, but not mannitol, rapidly and reversibly decreases nasal PD in normal human subjects.

\section{Methods}

Nasal PD was measured using previously described methods [5, 7, 8]. Briefly, the exploring electrode consisted of a double lumen silicone rubber tube with the openings of both lumens at the same site, $3 \mathrm{~mm}$ from the tip. One lumen was filled with an equal mixture of saline and electrocardiography electrode cream, connected to a high impedance voltmeter via a silver/silver chloride electrode. The second lumen was perfused with the different solutions as outlined below, using a peristaltic pump which provided a continuous flow of $4 \mathrm{~mL} \cdot \mathrm{min}^{-1}$ throughout the perfusion period. The reference electrode consisted of a second silver/ silver chloride electrode placed over an area of abraded skin on the forearm, again connected to the voltmeter. Prior to recordings, the offset of the electrodes was measured and appropriate corrections made to recorded values. In all cases, the tests started with an initial period of stabilization using standard Krebs N[2-hydroxyethyl]piperazine-N-[2-ethanesulphonic acid] (HEPES) solution. Following stabilization of the nasal $\mathrm{PD}$, the diluent was changed to the various hypertonic solutions as indicated below, with different hypertonic responses measured on different days, in random order.

Perfusion commenced with Krebs HEPES solution of composition (mM): $\mathrm{Na}^{+} 140, \mathrm{~K}^{+} 6, \mathrm{Ca}^{2+} 2, \mathrm{Mg}^{2+}$ $1, \mathrm{Cl}^{-} 152$, glucose 10 and HEPES 10, titrated to $\mathrm{pH}$ 7.4. Hypertonic solutions were produced volumetrically, so that the total concentrations of $\mathrm{Na}^{+}$and $\mathrm{Cl}^{-}$ in the Krebs $+500 \mathrm{mM}$ saline were $640 \mathrm{mM}$ and $652 \mathrm{mM}$, respectively. In the dose response testing, the solutions were perfused sequentially as indicated. Due to the $3 \mathrm{~mL}$ dead space of the perfusion system, the new perfusate reached the catheter tip approximately $45 \mathrm{~s}$ following solution change. Fresh stock solutions were prepared daily and diluted as required. All solutions were perfused at room temperature $\left(21-23^{\circ} \mathrm{C}\right)$.

\section{Subjects}

Nonsmoking control subjects (4 female and 3 male, aged $18-40 \mathrm{yrs}$ ) with no history of respiratory disease were recruited from the hospital staff for testing. No subjects had undergone nasal surgery, and all tests were performed at least 4 weeks following an upper respiratory tract infection. The study was approved by the hospital ethics committee and all subjects gave written informed consent.

\section{Statistical analysis}

The two-tailed paired t-test was used for comparison and the null hypothesis was rejected at $\mathrm{p}<0.05$. For discussion purposes, increases and decreases refer to the absolute magnitude of the PD, which was lumen negative.

\section{Results}

Initial studies measured the response of the nasal epithelium to different concentrations of added $\mathrm{NaCl}$. Following stabilisation of the PD in the Krebs HEPES diluent, the nose was perfused for 3 minutes with each of the following solutions: Krebs +150 , Krebs +250 , Krebs +500 , Krebs $+1,200$ and Krebs $+2,000 \mathrm{mM}$ $\mathrm{NaCl}$. This was associated with significant $(p<0.05)$ decreases in the mean (SEM) nasal PD of 6.6 (1.5), 7.6 (1.6), $10.0(2.0), 13.1$ (2.9) and $14.8(3.2) \mathrm{mV}(\mathrm{n}=4)$ (fig. 1). As the higher concentrations of saline present in Krebs +1,200 and Krebs +2,000 $\mathrm{mM} \mathrm{NaCl}$ also resulted in subjective discomfort in the nose during the testing, a solution of Krebs $+500 \mathrm{mM} \mathrm{NaCl}$ was selected for further investigation. This gave approximately $70 \%$ of the maximal response without causing any discomfort. All subsequent studies of hypertonic saline in this paper were then performed with Krebs $+500 \mathrm{mM} \mathrm{NaCl}$.

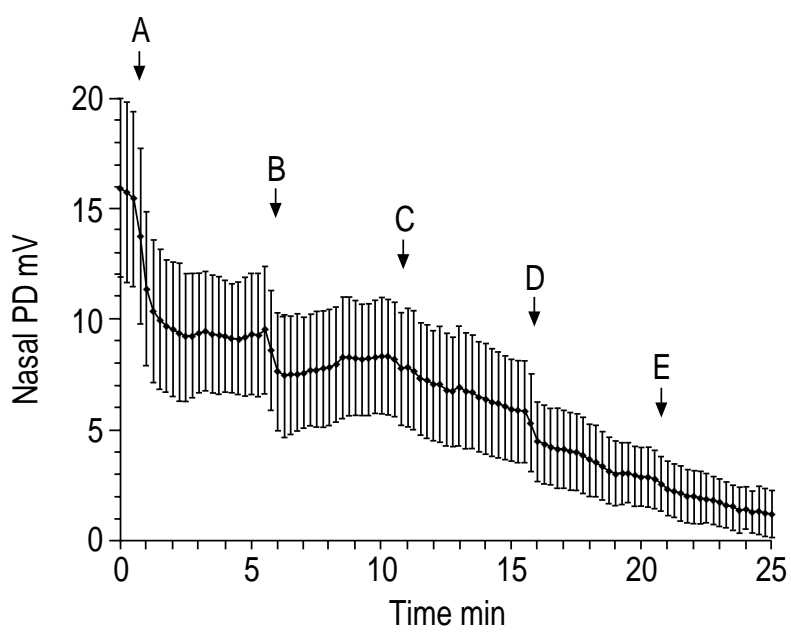

Fig. 1. - The effect of additional saline on the nasal potential difference (PD) in four normal subjects. Each new solution reached the nose approximately $45 \mathrm{~s}$ after the perfusate was changed, reflecting the dead space of the system. The solutions tested are indicated in the bar at the top of the graph. Data are expressed as mean \pm SEM. The PD is expressed in absolute terms, and was lumen negative. Arrows indicate $\mathrm{Krebs}+\mathrm{NaCl}$ solutions of the following concentrations; A: $150 \mathrm{mM} \mathrm{NaCl}$; B: $250 \mathrm{mM}$; C: $500 \mathrm{mM}$; D: $1.2 \mathrm{M}$; E: $2.0 \mathrm{M}$. 


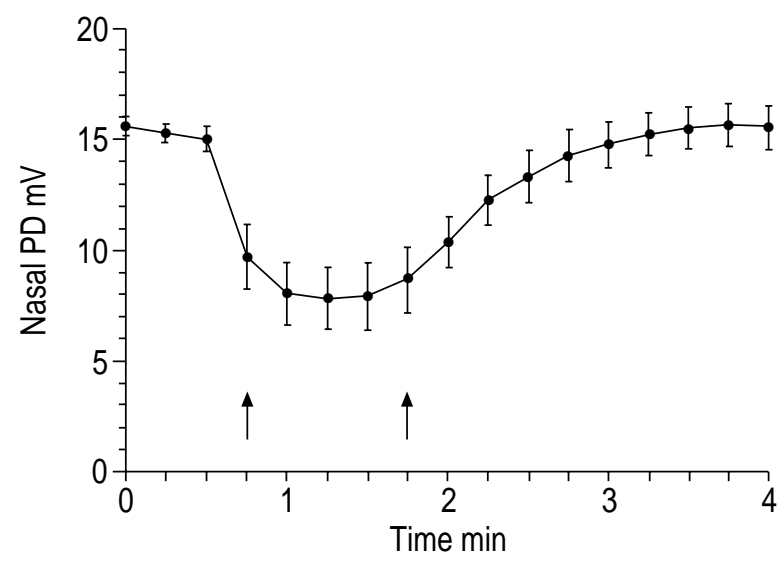

Fig. 2. - The effect of additional saline $(500 \mathrm{mM})$ added to the Krebs HEPES N-[2-hydroxyethyl]piperazine-N'-[2-ethanesulphonic acid], on the nasal potential difference (PD) in four normal subjects. The new solution reached the nose approximately $45 \mathrm{~s}$ after the perfusate was changed (indicated by arrows), reflecting the dead space of the system. After $1 \mathrm{~min}$ of perfusion with the hypertonic saline solution, the perfusate returned to Krebs HEPES diluent to assess the effect of washout. Data are expressed as mean \pm SEM. The PD is expressed in absolute terms, and was lumen negative.

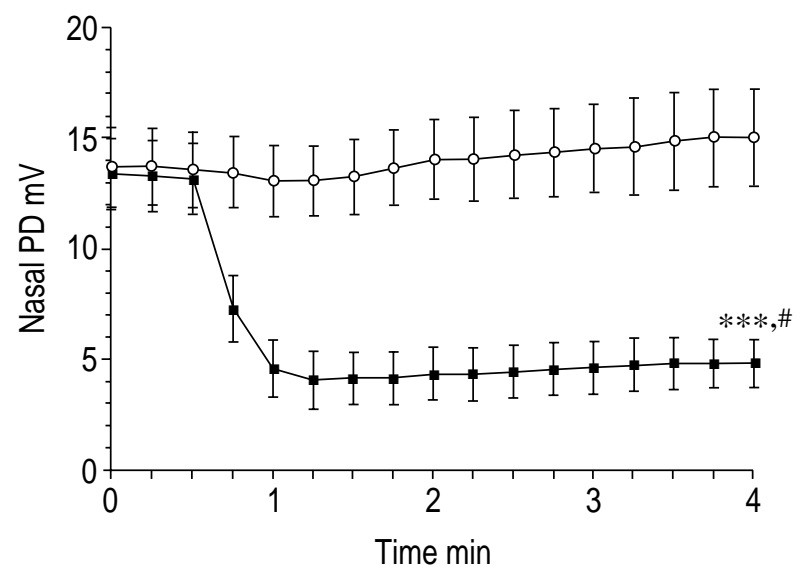

Fig. 3. - The effect of additional saline $(500 \mathrm{mM})$ or mannitol (1 M) added to the Krebs HEPES N-[2-hydroxyethyl]piperazine$\mathrm{N}^{\prime}$-[2-ethanesulphonic acid], on the nasal potential difference (PD) in 7 normal subjects. The new solution reached the nose approximately $45 \mathrm{~s}$ after the perfusate was changed, reflecting the dead space of the system. Data are expressed as mean + SEM. The PD is expressed in absolute terms, and was lumen negative. : saline; $\bigcirc$ : mannitol. ***: $\mathrm{p}<0.001$ versus baseline presaline; \#: $\mathrm{p}<0.0001$ versus mannitol.

To determine whether this response may be related to epithelial toxicity, the reversibility of the hypertonic saline response was measured. As shown in fig. 2, following $1 \mathrm{~min}$ of perfusion with Krebs $+500 \mathrm{mM}$ $\mathrm{NaCl}$, washout for $3 \mathrm{~min}$ reversed the response (presaline $15.9(0.5) \mathrm{mV}$, postwashout $15.8(1.1) \mathrm{mV},(\mathrm{n}=4))$.

In seven subjects the change to Krebs $+500 \mathrm{mM}$ $\mathrm{NaCl}$ was associated with a significant decrease in nasal PD from 13.7 (1.7) $\mathrm{mV}$ to $5.1(1.3) \mathrm{mV}(\mathrm{p}<0.001)$. This response was rapid in onset and sustained for at least $4 \mathrm{~min}$. In contrast, the addition of mannitol $(1,000 \mathrm{mM})$ to the perfusate did not significantly alter nasal PD, with a trend to an increase in the PD, (premannitol 13.9 (1.6) $\mathrm{mV}$, postmannitol 15.3 (2.0) $\mathrm{mV}, \mathrm{n}=7, \mathrm{p}=0.14)$ ), as shown in figure 3 .

\section{Discussion}

This study has demonstrated that topical application of hypertonic saline, Krebs $+500 \mathrm{mM} \mathrm{NaCl}$, corresponding to a stimulus of $\sim 3 \%$ saline, decreases nasal potential difference. The response to the hypertonic saline was rapid, reversible and dose related, suggesting a direct ion transport effect rather than nonspecific epithelial toxicity. In contrast, application of a similar osmotic load through hypertonic mannitol did not decrease the nasal PD, with a nonsignificant increase (more negative). This suggests that the ionic composition of the saline, and not the osmotic load, was involved in the saline response. As amiloride pretreatment can block the saline response in normal subjects (unpublished data), passive diffusion of $\mathrm{Cl}^{-}$ions down the paracellular pathway would not explain the changes in nasal PD. Therefore it is hypothesized that the saline directly alters ion transport processes across the normal human airway epithelium. This is the first demonstration in human subjects in vivo that increasing the $\mathrm{NaCl}$ concentration on the surface alters airway epithelial ion transport, independent of any effect of osmolarity.

Previous studies measuring the effect of hypertonic solutions on epithelial cells in vitro have found varying results. Early studies in canine trachea, a predominantly $\mathrm{Cl}^{-}$secreting epithelium, have shown that additional luminal $\mathrm{NaCl}(75 \mathrm{mM})$ decreased short-circuit current (Isc) and increased tissue conductance [9]. The decrease in $I$ sc predominantly reflected an increase in mucosal to serosal $\mathrm{Cl}^{-}$movement, which was proportional to the increased $\mathrm{Cl}^{-}$concentration on the mucosal surface. Interestingly, addition of $(150 \mathrm{mM})$ mannitol to the luminal surface decreased $\mathrm{Na}^{+}$absorption across the canine trachea without significant changes in either $\mathrm{Cl}^{-}$ movement or tissue conductance. MAN et al. [10] demonstrated that addition of $100 \mathrm{mM}$ mannitol to the luminal fluid decreased PD across the canine trachea by $3.9 \mathrm{mV}$, with a similar decrease in Isc. Interestingly there was a small increase in tissue resistance, opposite to the increased conductance found by YANKASKAS et al. [9].

In monolayers of cultured human nasal polyp cells, WiLLUMSEN et al. [11] measured the effects of raised luminal and serosal osmolality. Addition of $150 \mathrm{mM}$ mannitol to the luminal surface was associated with decreases (less negative) in both apical ( $V$ a $)$ and basolateral $(V \mathrm{~b})$ membrane potentials, with small but variable effects on the transepithelial membrane potential $(V \mathrm{t})$ in different monolayers. Addition of $75 \mathrm{mM} \mathrm{NaCl}$ to the luminal solution also decreased both $V_{\mathrm{a}}$ and $V \mathrm{~b}$, but did not alter $V_{\mathrm{t}}[11]$. The nonsignificant increase in nasal PD found in the current study corresponds with the variable effects on $V$ t found in the nasal polyp monolayers; $V$ a and $V \mathrm{~b}$ cannot be assessed using the nasal PD technique. Similarly, the changes in epithelial cell volume noted in the nasal polyp cultures cannot be measured by the current technique. Further studies will be necessary to deter- 
mine whether luminal mannitol does alter ion transport in vivo, with similar but opposite effects resulting in no significant overall response.

However, the responses to luminal saline appear to differ in the two studies with a significant decrease in nasal PD in the current study contrasting with the lack of change in $V$ t found by WILLUMSEN et al. [11]. This may simply reflect the different doses used in the respective studies - the only dose reported in the WILLUMSEN et al. study was $75 \mathrm{mM}$, whilst the smallest dose used in the current study was $150 \mathrm{mM}$. Another possible explanation for the differences between the two studies is the use of nasal polyp cells, which are known to exhibit ion transport processes which differ from those found in normal airway epithelial cells [12]. The nasal PD also avoids the difficulties of cell culture techniques, in particular the submersion culture process and the hormones and antibiotics required to maintain the cells in a viable state. Finally, another alternative may be the presence of hormonal factors which may control ion transport in vivo, but are not maintained when the cells are grown into monolayers in vitro. Irrespective of the basis for the differences between the in vivo and the in vitro studies, the current report provides important new information about the ion transport responses of the human airway epithelium in vivo.

The nasal PD response to increasing concentrations of $\mathrm{NaCl}$ in the current study corresponds with the doserelated effects of saline on mucociliary clearance. RoBINSON et al. [1] found that aerosols of $0.9 \%, 3 \%$, $7 \%$ and $12 \%$ saline were associated with isotope clearance at $90 \mathrm{~min}$ of $13 \%, 20 \%, 24 \%$ and $26 \%$, respectively. Whilst the MCC response may be related to the nasal PD effects demonstrated in the current study, there are a number of other possibilities, including increased ciliary beat frequency in vivo [13] and direct effects on sputum [14]. Furthermore, the divergent effects of hypertonic mannitol and saline on nasal PD do not correspond with the similar increases in MCC in a variety of clinical situations [3, 4, 15].

Hyperosmolarity is also a reliable stimulus to provoke bronchoconstriction in susceptible subjects. Hypertonic saline solutions have long been used in the laboratory as an indirect challenge agent, with more recent studies by ANDERSON et al. [16] studying the effects of inhaled mannitol. Whilst for the majority of subjects saline and mannitol produced qualitatively similar results, some subjects did show 10-fold higher sensitivity to one agent. Furthermore, EsCHENBACHER et al. [17] compared the effects of different solutions with the same osmolarity on the airways of asthmatic subjects. They demonstrated that 4\% saline solution was significantly more potent at inducing bronchoconstriction than $18.3 \%$ dextrose in $1 \%$ saline, though both solutions had the same osmolarity. Similarly MAGYAR et al. [18] has reported that $1.3 \mathrm{M} \mathrm{KCl}$ was more potent than $1.7 \mathrm{M} \mathrm{NaCl}$, (both solutions prepared at $10 \%$ weight/volume). This suggests that as well as the osmotic stimulus, the ionic composition may also be involved in bronchoconstrictor responses.

It is well recognized that both the osmolarity and ionic composition of an aerosol are important in the induction of cough. In an elegant series of experiments,
ESCHENBACHER et al. showed that hypertonicity, irrespective of ionic composition, induced both bronchoconstriction and cough [17]. Isosmotic saline solution induced neither bronchoconstriction or cough, but isosmotic dextrose, with a low $\mathrm{Cl}^{-}$concentration, induced cough in the absence of bronchoconstriction [17]. This suggests that hypertonicity and ionic composition can, in certain situations, be stimuli for different responses. The relationship between this and the nasal PD responses in the current study will require further investigation.

Finally, the differing nasal PD response to hypertonic saline and mannitol may have important implications for the development of new treatments for lung diseases. Clinical trials will be necessary to investigate each hypertonic solution individually, as the results from hypertonic saline and mannitol are not always interchangeable.

In conclusion, this study has demonstrated that topical application of hypertonic saline induces a rapid and reversible decrease in nasal potential difference in vivo, most likely reflecting altered ion transport across the human airway epithelium. The nonsignificant increase in nasal potential difference seen with hypertonic mannitol suggests that the two solutions exert different effects on the epithelium, dependent on their composition. Further studies are necessary to investigate the mechanisms involved in these responses.

\footnotetext{
Acknowledgements. The authors would like to thank the subjects who took part in this study, and E. Alton and S. Anderson for helpful discussions.
}

\section{References}

1. Robinson M, Hemming AL, Regnis JA, et al. Effect of increasing doses of hypertonic saline on mucociliary clearance in patients with cystic fibrosis. Thorax 1997; 52: $900-903$.

2. Eng PA, Morton J, Douglass JA, Riedler J, Wilson J, Robertson CF. Short-term efficacy of ultrasonically nebulized hypertonic saline in cystic fibrosis. Pediatr Pulmonol 1996; 21: $77-83$.

3. Robinson M, Daviskas E, Eberl S, et al. The effect of inhaled mannitol on bronchial mucus clearance in cystic fibrosis patients: a pilot study. Eur Respir J 1999; 14: $678-685$.

4. Daviskas E, Anderson SD, Eberl S, Chan H-K, Bautovich G. Inhalation of dry powder mannitol improves clearance of mucus in patients with bronchiectasis. Am J Respir Crit Care Med 1999; 159: $1843-1848$.

5. Middleton PG, Geddes DM, Alton EWFW. Trimethoprim and tetracycline inhibit airway epithelial sodium absorption. Am J Respir Crit Care Med 1996; 154: $18-23$.

6. Smith SN, Middleton PG, Chadwick S, et al. The in vivo effects of milrinone on the airways of cystic fibrosis mice and human subjects. Am J Respir Cell Mol Biol 1999; 20: 129-134. 
7. Middleton PG, Geddes DM, Alton EWFW. Effect of amiloride and saline on nasal mucociliary clearance and potential difference in cystic fibrosis and normal subjects. Thorax 1993; 48: 812-816.

8. Middleton PG, Caplen NJ, Gao X, et al. Nasal application of the cationic liposome DC-Chol:DOPE does not alter ion transport, lung function or bacterial growth. Eur Respir J 1994; 7: 442-445.

9. Yankaskas JR, Gatzy JT, Boucher RC. Effects of raised osmolarity on canine tracheal epithelial ion transport function. J Appl Physiol 1987; 62: $2241-$ 2245.

10. Man SFP, Hulbert W, Park DSK, Thomson ABR, Hogg JC. Asymmetry of canine tracheal epithelium: osmotically induced changes. J Appl Physiol 1984; 57: $1338-1346$.

11. Willumsen NJ, Davis CW, Boucher RC. Selective response of human airway epithelia to luminal but not serosal solution hypertonicity. Possible role for proximal airway epithelia as an osmolality transducer. J Clin Invest 1994; 94: 779-787.

12. Bernstein JM, Yankaskas JR. Increased ion transport in cultured nasal polyp epithelial cells. Arch Otolaryngol Head Neck Surg 1994; 120: 993 -996.
13. Wong LB, Miller IF, Yeates DB. Pathways of substance $\mathrm{P}$ stimulation of canine tracheal ciliary beat frequency. J Appl Physiol 1991; 70: 267-273.

14. Wills PJ, Hall RL, Chan W, Cole PJ. Sodium chloride increases the ciliary transportability of cystic fibrosis and bronchiectasis sputum on the mucus-depleted bovine trachea. J Clin Invest 1997; 99: 9-13.

15. Daviskas E, Anderson SD, Gonda I, et al. Inhalation of hypertonic saline aerosol enhances mucociliary clearance in asthmatic and healthy subjects. Eur Respir $J$ 1996; 9: 725-732.

16. Anderson SD, Brannon JD, Spring J, et al. A new method for bronchial-provocation testing in asthmatic subjects using a dry powder mannitol. Am J Respir Crit Care Med 1997; 156: 758-765.

17. Eschenbacher WL, Boushey HA, Sheppard D. Alteration in osmolarity of inhaled aerosols cause bronchoconstriction and cough, but absence of a permeant anion causes cough alone. Am Rev Respir Dis 1984; 129: 211-215.

18. Magyar P, Dervaderics M, Tóth A. Bronchial challenge with hypertonic $\mathrm{KCl}$ solution in the diagnosis of bronchial asthma. Schweiz Med Wochenschr 1984; 114: 910-913. 